\title{
Could the increased use of e-bikes (pedelecs) in Sweden contribute to a more sustainable transport system?
}

\author{
Lena Winslott Hiselius, Åse Svenssona \\ Lund University, Box 118, SE-221 Lund, Sweden
}

\begin{abstract}
The transport sector accounts for large proportions of greenhouse gas emissions and energy usage in Sweden, about $40 \%$ and $30 \%$, respectively. Most of this, $93 \%$, comes from road transports. There is, therefore, a strong political desire to reduce the use of fossil fuels in road transport. Several alternatives to fossil fuels have been discussed and, more recently, interest in electrically driven vehicles has increased substantially. Numerous studies have been made with respect to electric cars, but there is insufficient knowledge about the use of electrically assisted bicycles. With increased knowledge of the potential of these new bicycles, society can better meet the new trend. The main aim here is to present the effects of pedelec (in this paper referred to as e-bike) usage on $\mathrm{CO}_{2}$ emissions. Based on a web questionnaire sent to users of /e-bikes, this paper also attempts to gain insight into the actual usage and users' motives for buying e-bikes. The survey uses a sample consisting of customers who bought e-bikes through a retailer in Sweden. The results indicate that, contrary to other European studies, the majority of users switched from using their cars to e-bikes. Furthermore, most of the users were men with a driver's license and good access to a car. Calculations suggest that there are large gains to be made in terms of decreased $\mathrm{CO}_{2}$ emissions through a reduction in car mileage. Considering the $\mathrm{CO}_{2}$ reduction potential, and that e-bikes seem to attract men with good access to a car, the results are very interesting indeed. However, the survey is based on a small sample from a single retailer, and to what extent these users mirror the average e-bike user in Sweden is open to question. On the other hand, there is scant evidence to suggest that this would not be the case if standardized e-bikes are focused on.
\end{abstract}

Keywords: Pedelec; Sustainability; Travel Behaviour.

\section{Introduction}

Transport has become a world-wide issue of environmental and social concerns, due to problems of traffic safety, pollution (both air and noise) and health [1,2]. On a global scale, the transport sector contributes ca. 13\% of greenhouse gas emissions [3], much of it occurring in cities and urban areas. In Sweden, road transport accounts for ca. $25 \%$ of all energy consumption and ca. $30 \%$ of all CO2 emissions [4], implying that it is responsible for a substantial part of Sweden's climate emissions as well as other environmental problems. Thus, actions to reduce the environmental impact of road traffic in urban areas are very urgent.

Electrically assisted bicycles, along with electric cars, have important roles to play in solving the issue of climate-smart transport needs of the future. Indeed, such bicycles have become a fairly common mode of transport in the Netherlands and Germany, and are deemed to have great potential on a global scale. About $70 \%$ of the e-bikes in the EU are sold in Germany and the Netherlands. Around $20 \%$ of all new cycles sold in the Netherlands are e-bikes, representing a third of the total revenue from bicycle sales [5]. In Germany, 310,000 electrically assisted bicycles were sold in 2011 [6], corresponding to $8 \%$ of all cycles sold. The general prediction is that the number of electrically assisted bicycles sold will increase to 600,000 per year, which will constitute a market share of 10-15\%. While there are no precise figures for the distribution between electric assisted bikes (pedelecs) with motor assistance up to $25 \mathrm{~km} / \mathrm{h}$ and bikes with motor assistance up to 45 $\mathrm{km} / \mathrm{h}$, the consensus of opinion is that $95-98 \%$ of the electrically assisted bicycles sold are of type pedelecs. The figures for Sweden show that only a small fraction of the roughly 500,000 new cycles sold every year are electrically assisted bicycles. A travel survey in south-east Sweden [7] revealed that only about $1.3 \%$ of the surveyed households had access to an electrically assisted bicycle, but, on a more positive note, sales are expected to rise substantially in the future.

Corresponding author: Lena Winslott Hiselius. E-mail address: lena.hislius@tft.lth.se

http://dx.doi.org/10.3846/enviro.2014.119

(C) 2014 The Authors. Published by VGTU Press. This is an open-access article distributed under the terms of the Creative Commons Attribution License, which permits unrestricted use, distribution, and reproduction in any medium, provided the original author and source are credited. 
Compared to a conventional cycle, an electrically assisted bicycle provides extra power when riding into headwinds or up steep hills. To avoid arriving hot and sweaty, some people prefer cars to bicycles; they may well consider making the electrically assisted bicycle their choice of transport mode for at least some of their journeys. In fact, these bicycles could encourage already established cyclists to take on longer distances and arrive faster at destinations than with a conventional cycle. A very welcome side effect is that older cyclists with access to an electrically assisted bicycle can remain mobile longer.

Demonstration projects on the use of e-bikes have been carried out in Sweden, many with local authorities playing an active part, for example [8] and [9]. These demonstration projects, by definition, focus on smaller groups who may borrow or hire an e-bike for private and/or commuting purposes for a limited period. So far, no Swedish study has been directed at users who have bought e-bikes and are not participants in any special projects.

General studies (as opposed to demonstration projects) have been conducted in countries with a larger number and longer experience of e-bikes, e.g. Holland [10,11] and China [12], in order to acquire more information on who buys an e-bike, how the cycles are used and what modes of transport are replaced by them. Despite the great interest shown in conducting such studies, some researchers, for example Roetynck [13], maintain that there is too little research on e-bikes users.

In Roetynck [13], published as part of the EU project PRESTO, reference is made to accessible data showing that e-bike users consist of two main groups: older people, i.e. $\geq 65$, and commuters. There appears to be a tendency for the average age of those who buy such cycles to fall, an important reason being that increasingly more people are becoming aware of the advantages of an e-bike as a mode of commuter transport. Engelmoer [10] confirms that the conventional picture of this type of bicycle, i.e., it is an attractive alternative mainly for older people, is beginning to change, and that it is also attracting the interest of other age groups, as an environmentally friendly and flexible alternative to the car. Koucky and Ljungblad [14] point out that the average age of the users is starting to fall, which may be explained by the increasing share of commuters among buyers of e-bikes, and that new customer groups are becoming aware of the bicycles.

Studies show that it is mostly cycle journeys that are being replaced by e-bikes, and primarily for commuting [10]. The age groups that buy these cycles vary somewhat. Some studies maintain that a larger number of older people and people with physical impairment change to e-bikes when it becomes too difficult for them to use an ordinary cycle [13]. Other studies claim that younger people acquire the bicycles in order to transport heavier loads than they can manage with a conventional cycle, for instance by attaching a trailer [15]. The shorter journey time is also considered to be an important reason for obtaining an e-bike [12].

The tendency for it to replace the conventional bicycle, discussed e.g. in Engelmoer [10], implies both positive and negative effects: Positive in that some groups can extend their mobility when it becomes too difficult to use an ordinary bicycle, and negative in that people who are perfectly capable of using an ordinary bicycle change to using an electrically assisted bicycle. In the latter case, energy use is increased at the same time as physical activity is decreased.

The present study is the first scientific study in Sweden to address the electrically assisted bicycle user who has obtained his bicycle privately, i.e., without being associated with a demonstration project. The main aim of the study is to present more knowledge of electrically assisted bicycle users in Sweden: who they are, what their motives for acquiring the cycle are and how it is used. A calculation of the change in $\mathrm{CO} 2$ emissions, in terms of the use of the cycle compared to the previous mode of transport, is then used as the basis for the concluding discussion of future strategies to achieve a more sustainable transport system.

The material is based on a web questionnaire to customers who have bought an e-bike (of the type pedacles) from a retailer of electric bicycles in Sweden. We must point out, though, that this is a smaller study of users, and as such little is known about how representative it is of the typical user in Sweden. The retailer has good geographical coverage with outlets in several places, in addition to sales on the Internet. Notwithstanding, the retailer has no special models, which implies that we probably lack the variety of users, for instance the elderly and people with physical impairment, who are included in larger European studies [11].

\section{Method}

The use of electrically assisted bicycles is surveyed via a questionnaire sent to purchasers of an e-bike of the type pedacles. They are classified as follows: the electric motor is engaged only when pressure on the pedals is increased, i.e., it is disengaged when the cyclist stops pedaling; the motor only adds to the force of the pedals and does not provide any power at speeds over $25 \mathrm{~km} / \mathrm{h}$, and the motor's net effect does not exceed $250 \mathrm{~W}$.

The questionnaire contained several questions on the background of the participants, e.g. age, residence, driving license, occupation, technological interests and general effects of cycling such as less physical activity, greater accessibility, perceived security etc. Some of the questions dealt with their experience of the electrically assisted bicycle, how long they have had it, and factors that limit its use, for example battery power and weight. The rest of the questions were on how the bicycle was used, for what type of journey, distances cycled and how the journeys were made before it was acquired.

Through the retailer we gained access to over 1300 e-mail addresses of people who had bought an e-bike. After sending out the questionnaire, we noticed that the e-mail addresses were also for customers who had only sought information, or had contacted the retailer for some other reason. Hence, the number of e-bike buyers was considerably fewer than the number of addresses. Since we do not know how many actually bought an e-bike, we find it difficult to calculate the percentage of responses. We received 321 questionnaires in all. 
The analysis has been conducted through comparison of the group that changed from cars to e-bike with the group that changed from an ordinary cycle. References are made to possible differences in background data on an individual level, motive for acquiring an e-bike, the effects of using such a bicycle and how it is used.

\section{Results}

\subsection{Individual data}

Table 1 presents the statistics of various background variables for those who answered the questionnaire. Of these, the majority was men. As expected there are no e-bike users aged 18 and below. For the other age groups; 19-34 is underrepresented, 35-49 and 50-64 are overrepresented while $\geq 65$ is fairly equal compared to the general distribution in Sweden. The overwhelming majority had driving licenses and constant access to a car. About the same number lived in the countryside as in urban areas and large cities together. Compared to the average for Sweden, those who lived in the rural areas were overrepresented and those in the large cities underrepresented. On average, e-bike users have had their bicycles for three years, implying that most of them have managed to gain experience of using them. The number of owners also correlated well with the sales trend in Sweden.

Table 1. Background information for the dataset

\begin{tabular}{llll}
\hline Category & Distribution & Category & Distribution \\
\hline Gender & $24 \%$ & License & \\
Women & $76 \%$ & Yes & $93 \%$ \\
Men & & No & $7 \%$ \\
& & & \\
Age & & Access to car: & \\
$\leq 18$ & $0 \%$ & Always & $75 \%$ \\
$19-34$ & $9 \%$ & Often & $10 \%$ \\
$35-49$ & $33 \%$ & Seldom & $10 \%$ \\
$50-64$ & $35 \%$ & Never & $5 \%$ \\
$\geq 65$ & $23 \%$ & & 3 years \\
Residence & & & average \\
City & $26 \%$ & Ownership: & \\
Urban & $23 \%$ & & \\
Country & $51 \%$ & & \\
\hline
\end{tabular}

\subsection{Motive}

The respondents were asked to state their position on several statements regarding their reasons for acquiring an e-bike. The statements concerned both personal characteristics and the bicycle's qualities. The responses were graded on a 5-point scale ranging from "I do not agree at all" to "I agree absolutely", and were divided into age groups in order to capture any possible differences between the groups. The same age groups as in Table 1 were used.

I acquired an e-bike because I find it difficult to use an ordinary cycle due to my age or physical impairment. The majority, $56 \%$, stated that they did not agree at all with the statement, while $16 \%$ said they agreed absolutely. The fact that age is significant is manifested in the decreasing share of those who stated they did not agree at all, from $80 \%$ in the age group $19-34$ to $33 \%$ in the age group $\geq 65$. Correspondingly, the share who agreed absolutely increased from $4 \%$ in the age group $19-34$ to $23 \%$ in the age group $\geq 65$.

I acquired an e-bike to be able to carry heavier things on the cycle. $60 \%$ did not agree with the statement, $26 \%$ agreed and the rest (14\%) were neutral. When the results are analyzed in terms of age, it becomes clear that who is asked plays a significant role. The youngest age group, 19-34, and the oldest, $\geq 65$, had very similar views on this aspect, and both groups were substantially more positive compared to the two other age groups. For the youngest age group, the "heavier things" could refer to having a child on the cycle and, for the oldest group, the problems of carrying heavy things on a conventional bicycle are quite obvious.

I bought an e-bike because it is difficult when it is windy and when it rains: $58 \%$ agreed they had bought the e-bike because it was difficult to use an ordinary cycle in the wind and rain, $23 \%$ did not agree and the rest (18\%) remained neutral. Again, age played a role in how they answered. The age group that stuck out most in relation to the others was the 19-34 group in which as many as $36 \%$, of which $24 \%$ did not agree at all, did not agree with the statement, while $48 \%$ did agree. 
I acquired an e-bike to reduce my travelling time compared to an ordinary cycle: Equally large shares, of about $42 \%$ each, agreed and disagreed. However, there seemed to be a certain correlation with age. For the older age groups, the time reduction through using the e-bike was not as large as it was for the age group 19-34, of which no fewer than $71 \%$ agreed with the statement.

I obtained an e-bike because I'm environmentally conscious and will therefore use my car less: A majority, 58\%, agreed with the statement, $26 \%$ did not agree, and 16\% remained neutral. In terms of age, there did not appear to be great differences in the responses to these statements.

I bought an e-bike because I'm interested in the technology: 57\% agreed, but $24 \%$ did not. As many as $80 \%$ of the younger age group 19-34, agreed with the statement.

\subsection{Changed travelling behavior}

Previous studies from other countries show that it is mainly conventional cycles that are replaced by electrically assisted bicycles. By contrast, participants in our web questionnaire exhibit a different behavior. Figure 1 clearly illustrates that, depending on type of errand, $47-67 \%$ of the participants replaced their cars with e-bikes. Walking was the activity that decreased the least; $3-12 \%$ of the e-bike journeys replaced walking. A conventional bicycle was previously used for $15-26 \%$ of these journeys, and $4-16 \%$ of the journeys were previously undertaken by public transport.

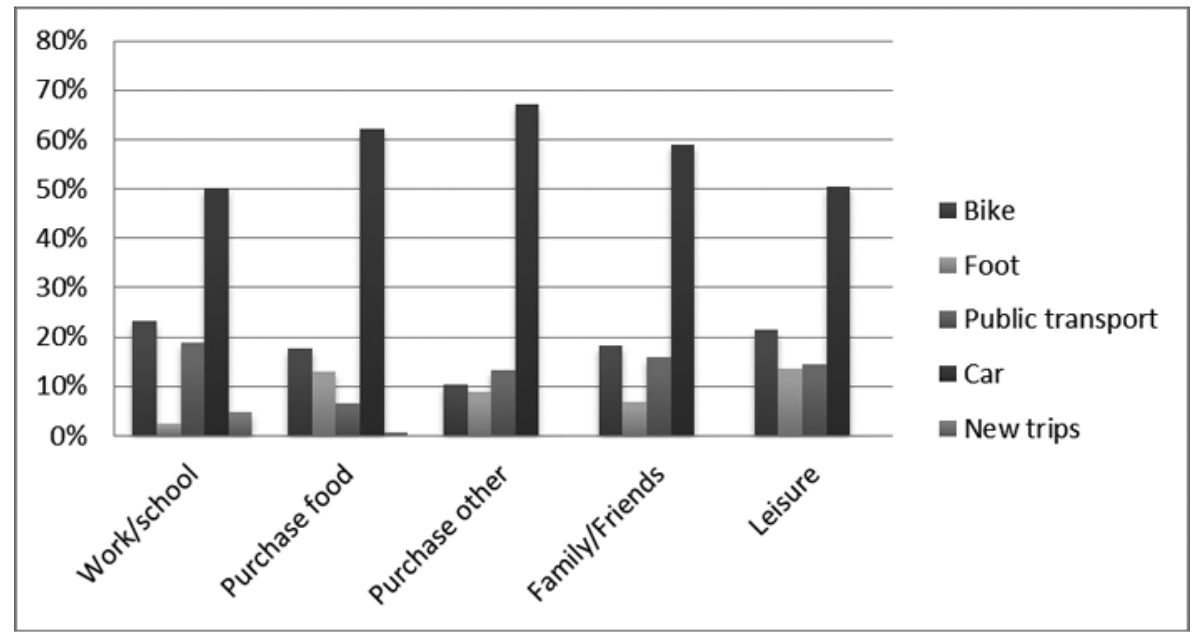

Fig. 1: Percentages distribution of the total number of e-bike journeys according to errand and transport mode

Table 2 presents the results of previous travelling distances (average of all the errands and and both distance and frequency of travelling taken into account) per person and week and previous mode of transport. The table also shows that $72 \%$ of the travelling distances were previously undertaken by car, $18 \%$ by public transport and $10 \%$ by ordinary cycle.

Table 2. Average number of kilometers per person and week before e-bike use according to previous transport mode

\begin{tabular}{lllll}
\hline \multicolumn{2}{c}{ Distance before e-bike use } & \multicolumn{2}{l}{ Distance with e-bike } \\
\hline Walking and cycling & Public transport & Car & Total & E-bike \\
6.94 & 12.65 & 50.28 & 69.87 & 70.87 \\
$10 \%$ & $18 \%$ & $72 \%$ & & \\
\hline
\end{tabular}

The average number of kilometers per person and week with the e-bike shows an average distance travelled (average of all the errands and taking into account distance and frequency) of 70.87 person kilometers. That is, the distance with the e-bike is marginally longer per day (both frequency and distance included).

\subsection{Calculation of carbon dioxide emission}

To calculate the $\mathrm{CO}_{2}$ emission of transportation per person per day, we use the Swedish emission factors for cars and public transport, and assume that walking and cycling are emission free. The emission factor for cars is $0.14 \mathrm{~kg} / \mathrm{km}$ per person with the assumption of a capacity utilization of 1.2 for each journey [16]. Since public transport is not divided according to the type of vehicle used, the emission factor for public transport is calculated as a balanced average of emission factors for different transport modes, based on the share of public transport modes in 2011 and in accordance with the Swedish national travel survey. This results in an emission factor of $0.033 \mathrm{~kg} / \mathrm{km}$ per person for a public transport journey. 
Based on changes in frequency, distance travelled and modal split, (results in Table 2) the $\mathrm{CO}_{2}$ emission is reduced by $327 \mathrm{~kg}$ per person per year. This represents $17 \%$ of the total $\mathrm{CO}_{2}$ per person from transports in Sweden [17].

In order to calculate the result for Sweden as a whole, we make an assumption of the total number of e-bike owners in Sweden today. Based on the sales figures and previous studies such as the travel survey in south-east Sweden [7], we assume that $1 \%$ of Sweden's population have an e-bike, which gives us a total of just over 95000 , see Table 3 . The total $\mathrm{CO}_{2}$ reduction resulting from e-bike use is almost 37000 tons $\mathrm{CO}_{2}$ per year.

We also calculate the reduced $\mathrm{CO}_{2}$ emission based on the assumption of the number of e-bike users in Sweden in 2030 , and assume that the social structure will not have changed significantly by then, implying that the modal split for different types of errands and travelling distances will not have changed much either. The low uptake estimate builds on the assumption that the number of e-bike owners in Sweden in 2030 will be equivalent to $5 \%$ of the population, which is today's figure for the number of owners in Holland [5]. The high uptake estimate builds not only on the assumption that the share of e-bike owners will be $10 \%$, but also on the forecast for Holland [5].

To isolate the effect of an increased share of these bicycle users from the effect of more efficient vehicles, we carry out a calculation with the assumption of unchanged emission factors.

Table 3. Estimated number of e-bikes and reduced $\mathrm{CO}_{2}$-emission in Sweden 2012 and 2030.

\begin{tabular}{llll}
\hline \multicolumn{2}{l}{ Total effect in Sweden 2012} & \multicolumn{2}{l}{ Total effect in Sweden 2030 } \\
\hline & & Low uptake & High uptake \\
\cline { 2 - 3 } Number of e-bikes & 95170 & 475850 & 951700 \\
Reduction of $\mathrm{CO}_{2}$ & 36902 tons/year & 184509 tons/year & 369017 tons/year \\
\hline
\end{tabular}

\section{Summary and discussion}

This study has provided us with a considerable amount of knowledge about e-bike users in Sweden. According to our data material, the user group is mainly made up of men with access to a car, and with a slight overrepresentation of people aged 35-64 compared to the general distribution in Sweden. Ownership of e-bikes is quite evenly distributed for those over 35 years of age. The owners are interested in technology, and interest in the environment is a driving motive for acquiring the bicycle. Reduced travelling time seems to be of greater importance for the younger age group. The majority of the respondents, in particular the oldest age group, agree with the statement that the e-bike means less effort; the members of the oldest group also state that they have bought an e-bike because of their age or physical impairment.

The results show that the majority of the journeys replaced by e-bikes are car journeys, and that the majority of the drivers are men; the indication is thus that these bicycles can change the travelling behavior of this group. On the other hand, we do not know how representative the respondents to our questionnaire are. The users in our sample have bought their cycles from a retailer that does not belong to a low-price group, and does not sell special models targeting the elderly and people with physical impairment either. This means that we may have captured a non-representative sample of e-bike users, which in turn may lead to overestimation/underestimation of the effects of replacing car use with e-bike use. Still, the respondents are well spread out geographically, and we feel that there is little likelihood of a completely different pattern of use of such cycles bought from other retailers. It can also be argued that those individuals who are using the cycles today can be regarded as a pioneering group illustrating the potential of electrically assisted bicycles. A calculation of energy use, based on the assumption of the development of electrically assisted bicycle use to the year 2030, confirms that there are large energy gains to be made.

As the study has revealed, there are energy efficiency gains to be realized by an increased use of electrically assisted bicycles for private journeys. The question then is: What measures should be introduced to speed up and facilitate this transformation? The results of this study show that the infrastructure is important for storing and recharging the bicycles. It may well be that we have chosen a type of e-bike that is relatively expensive, but our results correlate with the results of other studies that point to the need to lock the more expensive bicycles at home as well as at the workplace/school, travel centers and shops. This applies to both private and work journeys.

Another important measure to facilitate the use of electrically assisted bicycles is to have clearly defined thoroughfares for cycle traffic, and separation not only of pedestrians from cyclists, but also faster electrically assisted cycles from slower conventional cycles. Several incidents have been reported in the questionnaire, with some caused by the rest of the traffic environment. Consequently, the electrically assisted bicycle's full potential cannot be fully realized in areas with dense pedestrian and cycle traffic. The level of service, comfort and convenience of such bicycles is greatest in designated areas outside the central city areas where the bicycle can be fully utilized.

Looking at the segment of electronically assisted bicycles used for private journeys, it is notable that those who previously used their cars for the journeys are largely men. One reason could be their interest in new technology. This is in line with the argument that is usually used to make the introduction of tramways attractive; that new technology attracts "men with briefcases". Possible measures with which to increase interest in the electronically assisted bicycle are to spread information on its uses, market the technology and demonstrate it. 
What must also be mentioned is the "risk" of attracting ordinary cyclists. In this case there will be increased environmental effects that might not be all that desirable. A method of avoiding this potential problem is to improve the quality of the transport system for the ordinary cyclists and thereby retain the attraction of the ordinary cycle. Hence, in addition to the measures normally taken to improve the infrastructure, ordinary cyclists should be provided with such things as suitable and secure cycle parking areas, and showering facilities at work.

\section{References}

[1] Banister, D. 2005 Unsustainable Transport-City transport in the new century. Routledge, London.

[2] Van Wee, B. 2007 Environmental Effects of Urban Traffic, in Gärling and Steg (Eds.). Threats from Car Traffic to the Quality of Urban Life Problems, Causes and Solutions. Elsevier, Amsterdam.

[3] IPCC, 2007 Climate Change 2007 - Mitigation of Climate Change. Intergovernmental Panel on Climate Change (IPCC), University Press, Cambridge

[4] Swedish Energy Agency, 2012. Transportsektorns energianvändning 2011.Report 2012:1.

[5] RAI Vereniging, 2013 Statistics Rijwiel en Automobiel Industrie Avaiable fron Internet: http://www.raivereniging.nl/actueel/go-mobility/go-mobilitynieuwsbrief/20130124-een-miljoenste-ebike-verkocht.aspx

[6] Gehlert, T.; Kühn, M.; Schleinitz, K.; Petzoldt, T.; Schwanitz, S.; Gerike, R. 2012. The German Pedelec Naturalistic Cycling Study - Study Design and First Experiences Proceedings, in International Cycling Safety Conference 2012, 7-8 November 2012, Helmond, The Netherlands.

[7] National Transport Administration. 2012. Resvaneundersökning i sydöstra Sverige; Blekinge, Småland och Öland.

[8] Gudjonsson, H.; Johansson, K. 2012. Elfordon i Malmö i familjen och på arbetet - erfarenheter av elbilar, elmopeder och elcyklar, Transport and Roads, Technology and Society, Lund University, Sweden.

[9] ELMOS Electric mobility in smaller cities. Available from Internet: http://energikontorsydost.se/uppdrag/transporter/elmos.php

[10] Engelmoer, W. 2012. The E-bike: opportunities for commuter traffic-The potentials of using electric bicycles and-scooters in commuting traffic in relation to energy use, local emissions and the accessibility of a compact Dutch city. Master Thesis Energy and Environmental Sciences. University of Groningen, Groningen, The Netherlands.

[11] Hendriksen, I.; Engbers, L.; Schrijver, J.; van Gijlswijk, R.; Weltevreden, J.; Wilting, J. 2008. Elektrisch Fietsen, Marktonderzoek en verkenning toekomstmogelijkheden, TNO-rapport KvL/B\&G/2008.067, Leiden

[12] Cherry, C.; Cervero, R. 2007. Use characteristics and mode choice behavior of electric bike users in China, Transport Policy 14: $247-257$. http://dx.doi.org/10.1016/j.tranpol.2007.02.005

[13] Roetynck, A. 2010 PRESTO Cycling Policy Guide - Electric Bicycles. Belgium

[14] Koucky, M.; Ljungblad, H. 2012. Elcyklar och cykelinfrastrukturen - Kräver elcyklar en förändring i hur vi planerar för cykel? Koucky \& Partners $\mathrm{AB}$, Report from CyCity, Sweden.

[15 Dill, J.; Rose, G. 2012. E-bikes and Transportation Policy: Insights from Early Adopters, in Transportation Research Board 91 th Annual Meeting, Washington DC, US, January 22-26, 2012

[16] National Transport Administration. 2009. Handbok för vägtrafikens luftföroreningar. Appendix 6 updated 2012 Avaiable from Internet: http://www.trafikverket.se/Privat/Miljo-och-halsa/Halsa/Luft/Dokument-och-lankar-om-luft/Handbok-for-vagtrafikens-luftfororeningar/

[17] WWF, 2010. Svenska kommuners koldioxidfotavtryck. Avaiable from Internet: http://www.wwf.se/source.php/1285817/Svenska\%20kommuners\%20koldioxidavtryck_FINAL_WWF-rapport_2010.pdf 